\title{
Dimensions of Children's Health Beliefs
}

\author{
T.E. Dielman, Ph.D. \\ Sharon L. Leech, M.P.H \\ Marshall H. Becker, Ph.D., M.P.H. \\ Irwin M. Rosenstock, Ph.D. \\ William J. Horvath, Ph.D. \\ The University of Michigan \\ Susan M. Radius, Ph.D. \\ Harvard University
}

ABSTRACT: Health beliefs interviews were conducted with 250 children aged 6-17 years. A factor analysis of the items resulted in six correlated factors which were interpreted as 1) specific health concerns, 2) general health concerns, 3) perceived parental concern, 4) perceived general susceptibility, 5) perceived susceptibility to specific conditions, and 6) perceived seriousness of and susceptibility to disease. Factor scores were computed and two-way analyses of variance (by age and sex of child) were conducted on six sets of factor scores. No significant sex differences or sex by age interaction effects were noted. Younger children scored significantly higher on "specific health concerns" and "perceived general susceptibility, "while older children scored significantly higher on "perceived parental concern." Tests of differences among variances showed a tendency for the variability to be greater among younger children. The results are interpreted as providing partial support for a model of children's health beliefs and as a basis for further operationalization of concepts which are central to an understanding of motivated health behavior. Implications for practice are discussed.

\section{THE HEALTH BELIEF MODEL}

Considerable research has been conducted on the health beliefs of adults, particularly with regard to understanding the roles played

Dr. Dielman is Associate Professor and Ms. Leech is a Research Associate in the Department of Postgraduate Medicine. Dr. Horvath is Professor of Psychiatry. All are with The University of Michigan School of Medicine. Drs. Becher and Rosenstoch are Professors in the Department of Health Behavior and Health Education. The University of Michigan School of Public Health. Dr. Radius is Assistant Protessor. Department of Behavioral Sciences. Harvard University School of Public Health. Reprint requests should be addressed to: Dr. T.E. Dielman, G-1210 Towsley, University of Michigan, Ann Arbor, Michigan 48109.

This research was supported, in part, by Crant No. MH-32210 from the National Institute of Mental Health. Grant No. IP50-N502013 from the National Center for Health Services Research, and Crant No. $5 \mathrm{KO}+$ HDOO237 from the National institute of Child Healthand Human Development. 
by those beliefs in guiding health-related behaviors. 'While a variety of relevant psychosocial models exist, ${ }^{2}$ the one which has, during the past decade received the greatest attention and empirical support is a formulation which has come to be known as the "Health Belief Model" (HBM). This model's approach is phenomenological in character, reflecting the influence of Lewin, and focuses on the current dynamics acting upon the behaving individual. ${ }^{3}$

In its most elemental form, the HBM postulates that the likelihood of an individual undertaking a recommended health action aimed at preventing or curing some disease or condition will depend (at least in part) on that individual's perceptions of: 1) personal susceptibility to the condition; 2) how serious an impact on one or more components of life the disease would have if contracted; 3) the probable benefits of the action (in terms of reducing susceptibility and/or severity); and 4) what barriers might exist to initiating or continuing the recommended action (e.g., cost, pain, danger, inconvenience, etc.). ${ }^{4}$

\section{Research on Adult Health Beliefs}

Recent reviews of research concerning the HBM list more than 30 studies in which the model's variables were found to be associated with such diverse health behaviors as participating in screening and immunization programs, obtaining preventive check-ups from physicians and dentists, keeping clinic appointments, and adhering to regimens prescribed for a variety of acute and chronic diseases. 5.6 A few studies have also provided evidence bearing upon the structure, validity, and reliability of the constructs employed in the model at the adult level."

Research on the HBM has focused more on developing concepts in the model than on methodological studies of the properties and dimensions of those concepts. This is quite understandable since, as recently discussed by Cummings et al., ${ }^{8}$ the iterative nature of science requires a constant shifting of attention between concepts and their measure. Despite the relative dearth of work on the structure, reliability, and validation of the model, it has yielded substantial evidence of utility in predicting health actions

Recently, however, more attention has begun to be directed toward identifying the structure of health beliefs. The previouslycited paper by Cummings et al. ${ }^{8}$ reflects such interest. That paper concluded that perceptions of susceptibility, severity, barriers, and benefits can be measured with substantial convergent validity using questionnaire items. At the same time, limitations in that research,especially regarding sampling, make it desirable to replicate the study using other samples and different content. 
As a parallel development, it may be noted that most of the research on the Health Belief Model has been restricted to the beliefs of adults. Research on the health beliefs of children is, however, quite scarce. (One reviewer" wrote that "Despite the voluminous literature on adult health and illness behavior no systematic studies to describe children's development of health and illness beliefs and behavior were found.")

\section{Needed Research}

It is of the greatest importance to study the origin and development of the health beliefs in children, if educators are to have any impact on the modification of health beliefs. While the relationships between beliefs and behavior in adults and in children are not always clear, the use of direct instructional activity will probably always remain the preferred method in the arsenal of educators. This is so because most educators place great value on increasing people's knowledge about health-related matters as a goal which is worthy of attainment in itself, as well as constituting a method for attaining the goal of behavior change

Working with children has the appeal, in principle at least, that the beliefs and attitudes of children are more malliable than those of adults, if only because children's beliefs have not become as firmly fixed. However, before pinpointed educational activities with children can be undertaken rationally, a number of questions need to be answered. We need to know, first, what children of various ages believe about their susceptibility to various ill health conditions. What do they believe about the severity of those conditions? What do they believe about the benefits associated with taking alternative actions to reduce the threat of disease? Second, we need to know whether the development of beliefs on these matters is associated with age - what is the lowest age at which children may profitably be taught health-related information that can serve them in subsequent years as they develop? Third, are there sex differences in the development of health beliefs? Do boys and girls develop their beliefs at different chronological ages?

In an effort to deal with such questions, the present study was undertaken. Before detailing the methods and findings of the present study, it would be well to review briefly the few studies on children's health beliefs that have been reported.

In an early study which attempted to assess the degree of influence mothers had in shaping their children's health attitudes and behaviors, Mechanic ${ }^{10}$ obtained data from 350 mother-child pairs. While analyses suggested that maternal influences on children's health beliefs were considerably less powerful and consistent than 
initially hypothesized, the findings also revealed that sex-role socialization processes appeared to affect the child's attitudes toward risk, denial of pain, and reluctance to report illness (male children were more stoic).

Gochman"11" and Gochman et al. 14 have conducted exploratory research on the developmental aspects of perceptions of vulnerability to disease. The general findings were that children are consistent in their perceptions of susceptibility to a variety of illnesses, accidents, and health problems, and that relatively older children exhibit greater consistency between their perceptions of vulnerability to ill health in the abstract and their estimates of vulnerability to specific illnesses. In a study of 108 children conducted at a summer camp Gochman ${ }^{15}$ was also able to show that the relationship between children's perceptions of vulnerability to health problems and potential health behavior was influenced by both degree of perceived internal control and salience of health. (The study's findings were consistent with the HBM.)

Several other investigations have shown that children's attitudes toward health are influenced by race and socioeconomic status;" by level of maturity: ${ }^{1-}$ and by anxiety level and present state of health. ${ }^{18}$

Lewis et al." studied the health-related beliefs and expectations of over 300 children who were observed for two years as part of a larger project to evaluate a program permitting child-initiated use of school nursing services. Some of the constructs examined were "definition of health," "past experiences, (with illness or injury)," "use of sick role," "locus of control," and such elements of the HBM as "perceived vulnerability (health status)," "perceived severity of illness/injury," "perceived benefits of care," and "knowledge/beliefs about health/disease." Results demonstrated that these constructs could be measured among the children studied, and also revealed that these health orientations were significantly altered by participation in the study.

Finally, Radius et al.2021 have presented results from initial analyses of data obtained in a survey of children's health beliefs/behaviors (on which the current report is based). These early reports noted that about half the children interviewed were not concerned about health matters (level of concern was independent of age and sex) and engaged in dysfunctional health behaviors.

The Radius et al. analyses employed single item measures, and sometimes summed measures into indices which were developed on an a priori basis. The objective of the analyses reported in this paper is to evaluate the construct validity, through factor analysis, of the items which were developed to measure dimensions of the HBM. The internal consistency (Cronbach alpha) reliabilities of the resulting multi-item scales are also presented. In addition, the main 
and interaction effects of age and sex on each of the constructs are examined.

\section{METHODS}

During April, 1977, a sample was drawn for a household interview survey of health beliefs, health behaviors, and health status in Washtenaw County, Michigan. A sampling rate of $1 / 68$ resulted in a total of 1,239 households selected for study. The sampling was conducted on a multi-stage probability basis. ${ }^{22}$ Since several institutions for higher learning are located in the area, households were defined as ineligible for the study if the primary adult respondent was residing in the county primarily for the purpose of attending a college or university. This criterion resulted in the deletion of 130 , or 10.5 percent, of the 1,239 households initially selected. Of the remaining 1.109 households, $109(9.8 \%)$ were refusals, and $146(1.3 .2 \%)$ were other sources of nonresponse (not at home after repeated calls, house vacant, etc.); the remaining 854 households (77.0\%) yielded completed interviews.

At least one adult in each household was interviewed; and, whenever there were children between six and 17 years of age in the family, one child was randomly selected for interviewing as well. Seven children $(2.7 \%)$ of the resulting sample of 264 refused to be interviewed, and another seven were not interviewed for other reasons (not at home after repeated calls, etc.), resulting in 250 completed interviews with the children.

All interviews were conducted in the household by trained interviewers Interviewing time with the children ranged from 15 to 55 minutes. One hundred and twenty-four of the children were six to 11 years of age; the remaining 126 were 12 to 17 years old

\section{RESULTS}

This section provides much detail on factor analyses which may be of particular concern to readers with methodological interests in the study of the structure of health beliefs. Those more concerned with the implications of the results may wish to devote more attention to the discussion section.

The first step in the analysis of the structure of the items was to calculate the interrelationships (Pearson product - moment correlations) among pairs of items. The next several steps were factor analytic procedures which were directed at describing these observed relationships in a parsimonious fashion. Technical details concerning the analysis and the documentation of each step are available from the senior author upon request. As a result of the factor analysis, six factors, or dimensions, of children's health beliefs were identified. These six factors accounted for 40 percent of the variance held in common by all of the items. These six factors were then rotated to maximize "simple structure," the criteria of which were proposed by Thurstone ${ }^{23}$ as a means of providing a parsimonious description of a greater number of observed relation- 
ships. Two types of factor rotation techniques were employed. First, the six factors were rotated to the Varimax criterion, which does not allow correlations among the factors. Subsequently, the Oblimin criterion was employed, which allows the factors to be correlated. As some of the factor intercorrelations resulting from the Oblimin rotations were substantially greater than zero, the Oblimin solution was selected for interpretation.

Table 1

Salient Factor Pattem Values $\left(v_{f p} \geq .25\right)$

For The Six Child Health Bellef Factors

Factor I: Specific Health Concerns (Alpha $=.77)$

Factor Pattern Value

When you are sick, how much do you worry about 1t? 39

How much trouble will catching a cold make for you? 49

How worried would you be if you got a headache? 55

How worried would you be if you got a cold? $\quad .67$

How worried would you be if you had a fever? .66

How worried would you be if you had something in your eye? $\quad .4$

How worried would you be if you were throwing up? 41

How wortied would you be if you had a pain in your stomach? $\quad .49$

How worried would you be if you fell of a bike? .51

How worried would you be if you had a tooth that hurt? .45

When you begin to feel a little sick, do you usually tell

someone about it right away or do you wait to see if the

feeling will go away?

Factor II: Perceived Susceptibility (Specific Conditions) (Alpha $=.67)$

How much of a chance do you think there is (in the next few months) that you might get a fever?

How much of a chance do you think there is (in the next few months) that you wight throw up?

How much of a chance do you think there is (in the next fer months) that you might feel dizzy?

How much of a chance do you think there is (in the next few months) that you wight have a pain in your stowach?

How much of a chance do you think there is (in the next few months) that you might have a tooth that hurts? 
Factor 1II: General Health Concern (Alpha $=.56)$

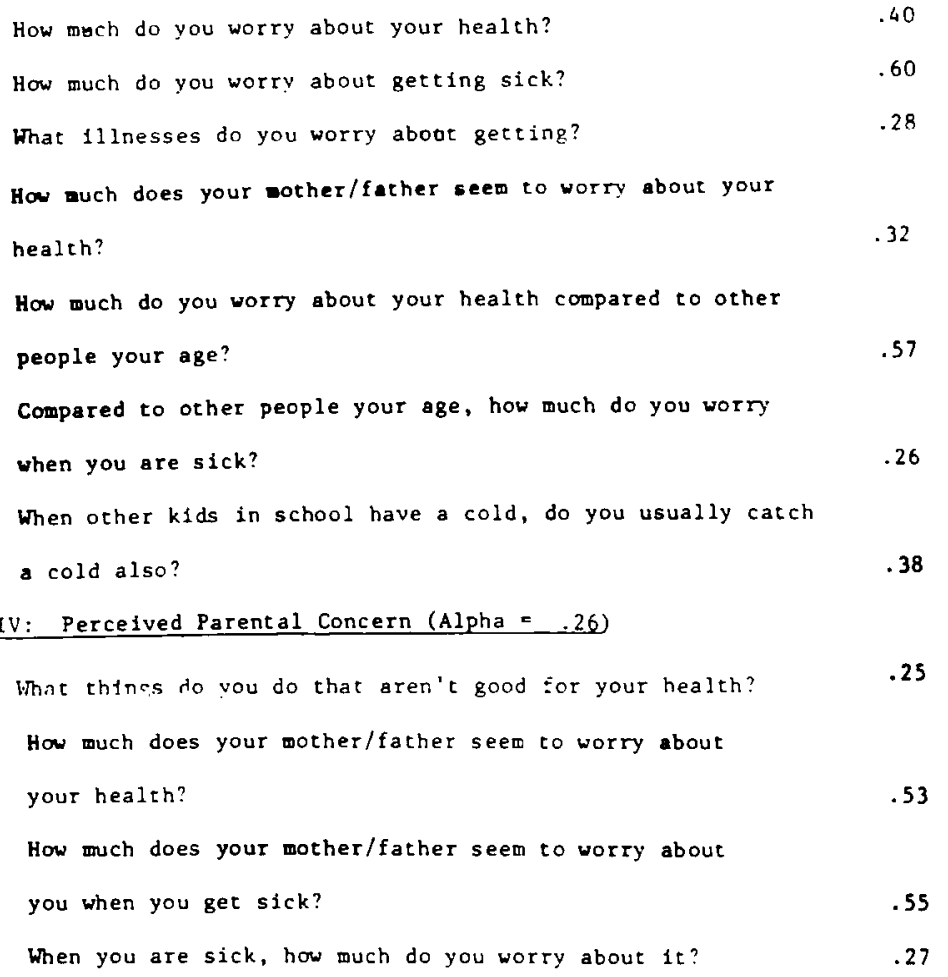

Table 1 presents the Oblimin factor pattern loadings which were equal to or greater than 25 for the six-factor solution. The first factor received its highest loadings from a series of questions concerning the degree to which the child said he/she would worry about specific problems, and has consequently been labeled "specific health concerns." The second factor's highest loadings were derived from a series of questions concerning the degree to which the child reported feelings of being susceptible to specific problems (labeled "perceived specific susceptibility"). The third factor's highest loadings came from items which indicated that the child worried more about health and health problems (designated "general health concern").

The highest loadings on the fourth factor were found to be those questions dealing with the child's perceptions of degree of parental concern about the child's health. (The negative loading obtained by the item "What things do you do that aren't good for your health?" indicates that children who reported greater parental concern tended also to report fewer negative health habits). This factor has been 
Factor V: Perceived Seriousness of and Susceptibility to Disease

$$
\text { (Alpha }=.43)
$$

When you're sick, how bad do you usually feel?

How worried would you be if you were feeling dizzy?

How much of a chance do you think there is (in the next

few months) that you will get something in your eye?

How much of a chance do you think there is (in the next

few months) that you will get a headache?

How wuch of a chance do you think there is (in the next

few months) that you will get a pain in your stomach?

\section{Factor VI: Percelved Susceptibllity (General)(Alpha - .65)}

In general, do you get sick a lot, sometimes, little, or hardly ever?

Bow often do you get sick compared to others your age?

When others in school have colds, do you usually catch a cold also?

How much of a chance do you think there is that you will get sick in the next month or 60 ?

How much of a chance do you think there is (in the next

few months) that you will catch a cold?

How much of a chance do you think there is (in the next

few months) that you will get a fever?

How much of a chance do you think there is (in the next

few months) that you will feel dizzy?

labeled "perceived parental concern." The fifth factor received its highest loadings from items concerning perceived susceptibility to, and perceived seriousness of, disease (as reflected by its title in Table 1). The sixth (and final) factor interpreted in this analysis has been labeled "perceived susceptibility (general)," as its highest loadings were contributed to questions which had been designed to assess that dimension.

The alpha coefficients associated with each of the six factors were computed among the unit-weighted items which were the primary 
marker variables for the factors, and are presented in Table 1 in parentheses following the factor designations. Alpha coefficients are estimates of the correlation of a test (or scale) with an alternate form of the same test (or scale) which contains the same number of items. The square root of the alpha coefficient is the estimated correlation of the test (or scale) with "errorless true scores" on a measure of a given concept. As such, the alpha coefficient is a validity coefficient. Nunnally ${ }^{24}$ recommends that the computations of alpha coefficients be routinely conducted when new measures are being developed. The coefficients ranged from 26 for Factor IV, "perceived parental concern," to .77 for Factor I, "specific health concerns."

Intercorrelations among the six primary factors are shown in Table 2. Moderate positive associations were obtained between factor I, "specific health concerns," and the "specific" and "general susceptibility" factors (II and VI), and the "general health concern" factor (III). The "general health concern" factor also correlates at a level of 27 with factor $V$, "perceived seriousness of and susceptibility to disease." The highest primary factor intercorrelation is that - .43 between factor II, the "specific susceptibility" factor, and factor III, "general health concern."

Factor scores were computed for each child by the full regression method of factor score computation. ${ }^{25}$ Subsequent to the computation of factor scores, two-way analyses of variance were conducted on each of the six sets of factor scores to test the main and interaction effects of sex and age of the children. For these analyses, children's ages were grouped $6-8,9-11,12-14$, and $15-17$ years. The analyses of variance revealed statistically significant $(p<.05)$ age effects for five of the six factors (the exception was "general health concern"). No sex effects nor age-by-sex-interaction effects were found. Consequently, the data were collapsed for males and females, and the results of the one-way analyses of variance by age for the six sets of factor scores are presented in Table 3.

The analysis of variance by age on the "specific health concerns" (factor I) scores produced a significant $(p<001)$ age effect. The after-the-fact comparisons for differences between pairs of means were conducted using the Scheffe' ${ }^{26}$ method, which minimizes the Type I error when conducting multiple comparisons (the maximum Type I error was set at .05 for all paired comparisons). Table 4 presents the results of these comparisons.

Paired comparisons of group means of the "specific health concerns" factor scores indicated that the means of the two older groups of children were significantly different ( $p<.001$ in all cases) from those of the two younger groups. However, the means of the 6-8 and 9-11 year old children were not significantly different from each other nor were the means of the 12-14 and $15-17$ year-olds. The 


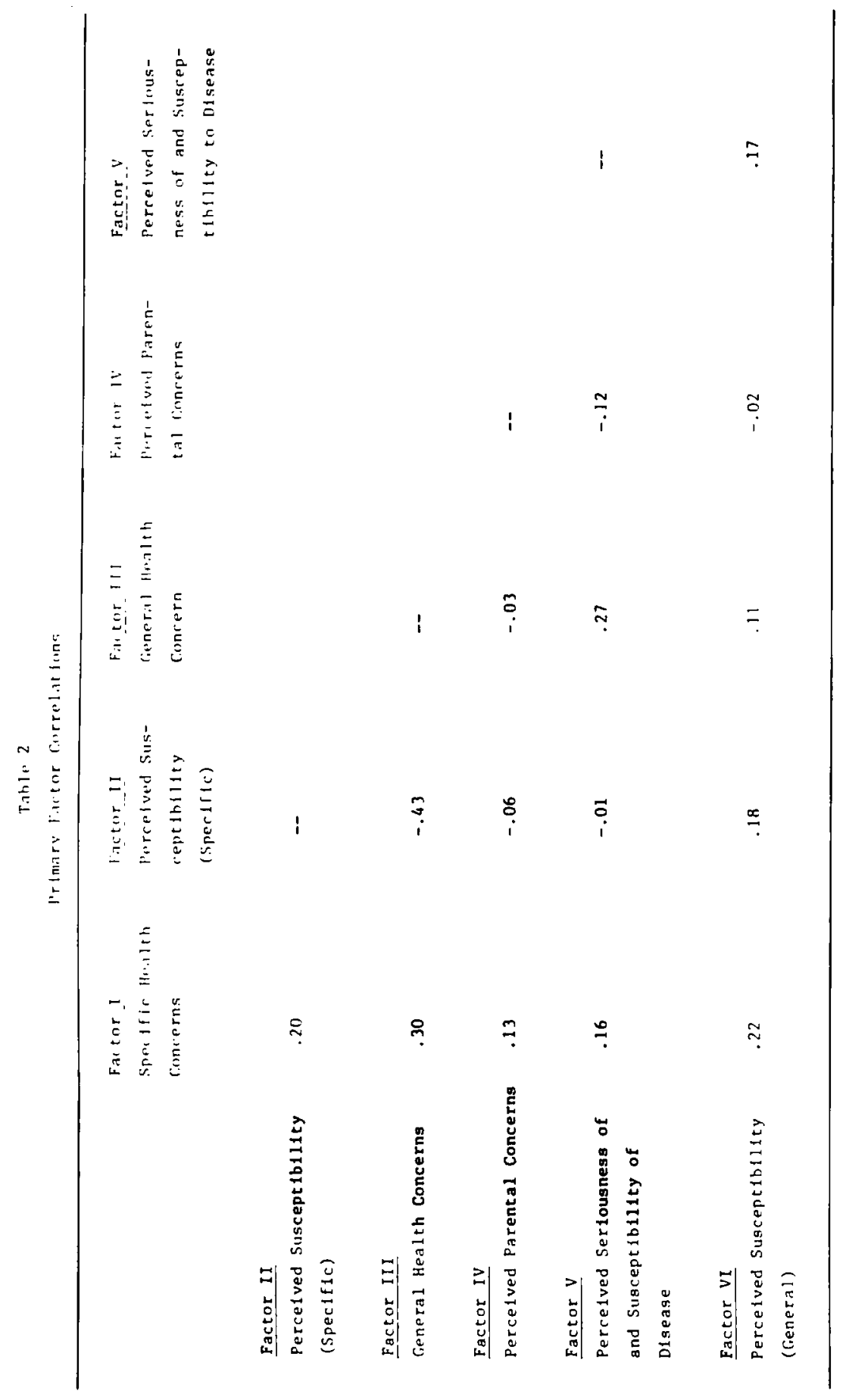




\section{Factor 1. Specific Health Concerns}

$\begin{array}{rrrrr}\text { Age Group } & 6-8 & 9-11 & 12-14 & 15-17 \\ \mathrm{~N} & 64 & 60 & 59 & 67 \\ 3.47 & 3.51 & 2.82 & 2.77 \\ & .87 & .86 & .96 & .75 \\ F=13.81, \mathrm{P}<.001, \mathrm{eta} & \end{array}$

Factor II. : - iceived Susceptibility (Specific Conditions)

$\begin{array}{lrrrr}\bar{X} & 3.52 & 3.94 & 3.58 & 3.70 \\ \text { SD } & 1.00 & .77 & .88 & .78\end{array}$

Factor III. General Health Concern

\begin{tabular}{lrrrr}
$\bar{X}$ & 2.66 & 2.86 & 2.51 & 2.48 \\
SD & .80 & .87 & .94 & .82 \\
\multicolumn{1}{c}{$r=2.52, p<06$, eta $^{2}=.03$} & &
\end{tabular}

\section{Factor IV. Perceived Parental Concerm}

$\begin{array}{lrrrr}\bar{X} & 2.63 & 3.31 & 3.14 & 3.33 \\ \text { SD } & .83 & .69 & .72 & .67 \\ & F=12.51, p<.001, \text { eta }{ }^{2}=.13\end{array}$

Factor V. Perceived Seriousness of and Susceftibility to Disease

$\begin{array}{lrrrr}\bar{X} & 3.20 & 3.65 & 3.28 & 3.34 \\ \mathrm{SD} & .82 & .74 & .72 & .74 \\ \mathrm{~F}=4.05, p<.01, \text { et }^{2}=.05 & & \end{array}$

Factor VI. Perceived Susceptibllity (General)

\begin{tabular}{lrrrr}
$\bar{X}$ & 3.05 & 2.90 & 2.38 & 2.14 \\
SD & .91 & .87 & .73 & .61 \\
\multicolumn{1}{c}{$\quad r=19.05, P<.001$, eta ${ }^{2}=.19$}
\end{tabular}


variance accounted for $\left(\mathrm{eta}^{2}\right)$ in "specific health concerns" by age was 14 percent.

The analysis of variance on "perceived susceptibility to specific conditions" (factor II) scores showed a significant $(p<.05)$ age effect, with three percent of the variance accounted for by the age of the child. The Scheffé tests among pairs of group means, however, did not show any significant differences at the .05 level. The analysis of variance of the "general health concern" (factor III) scores yielded an overall F-ratio that just fell short of statistical significance .05 $<p<.06$ ), even though the variance accounted for in the "general health concern" scores, when rounded to two decimal places, was equal to that accounted for in the "perceived susceptibility to specific conditions" scores (eta ${ }^{2}=.03$ in both instances).

The overall age effect for the "perceived parental concern" (factor IV) scores was significant beyond the .001 level, with age

Table 4

Results of Á Posteriori Comparisons Among Group Means

(Scheffé Tests)

Factor I. Specific Health Concerns

$\begin{array}{lccc}\text { Age Group } & 9-11 & 12-14 & \frac{15-17}{\star \star} \\ 6-8 & n s & \star \star \star & \star \star \star \\ 9-11 & -- & -- & \text { ns } \\ 12-14 & -- & \end{array}$

Factor II. Perceived Susceptibility (Specific Conditions)

No Significant Differences

Factor III. General Health Concern

No Significant Differences

Factor IV. Perceived Parental Concern

$6-8$

$9-11$

$12-14$

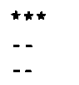

\#*

Factor V. Perceived Seriousness of and Susceptibility to Disease

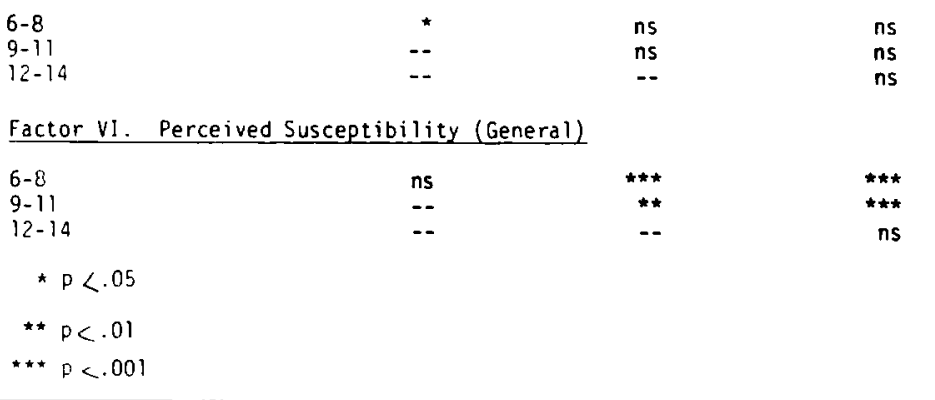


accounting for 13 percent of the variance. The mean score for the 6-8 year old children was significantly $(p<.01)$ lower than that obtained for any other age group. None of the other group means differed significantly when tested by the 'Scheffé procedure.

With respect to the factor $V$ scores, "perceived seriousness of and susceptibility to disease," five percent of the variance was accounted for, and the overall effect was significant beyond the .01 level. The only significant $(p<05)$ difference between pairs of means was between the 6-8 and 9-11 year old groups.

Age of the child accounted for 19 percent of the variance in the "perceived general susceptibility" (factor VI) scores. The age effect was significant at beyond the .001 level. The á posteriori tests among pairs of means again showed the two youngest groups to differ significantly $(p<.01)$ from the two older groups. The mean scores of the two younger groups were not significantly different from each other, nor were the means of the two older groups.

An issue apart from the level of the different age groups on the various health belief factors is the variability within age groups on the factors. Gochman ${ }^{12.14}$ has suggested that as children grow older there is more consistency and less variability in their health beliefs. To test this hypothesis on the factors which emerged in the current study, an overall comparison of the variances of the four age groups was made for each of the six sets of factor scores by Bartlett's test of homegeneity of variances. ${ }^{27}$ The values of the $V$ statistic were significant beyond the .01 level for each of the six factors. The null hypothesis of equal variances across age groups was thus rejected.

Comparisons of pairs of variance ratios by age group were then conducted for each set of factor scores. On factor I, "specific health concerns," the only significant ratio was between the $12-14$ year olds and the 15-17 year olds. On factor II, "perceived susceptibility (specific conditions)," the variance of the youngest group was significantly greater than those of the 9-11 year olds and the 15-17 year olds. On factor IV, "perceived parental concern," the variance of the youngest group was significantly greater than that of the oldest group. On factor VI, "perceived susceptibility (general)," the variances of the two youngest groups were significantly greater than that of the oldest group, and the variance of the youngest group was significantly greater than that of the 12-14 year old group. No significant ratios were noted for factors $I I I$ and $V$. These results are summarized in Table 5.

\section{DISCUSSION}

Factor analysis of questions representing theoretical constructs in the children's HBM resulted in a separation of items designed to 
Factor L. Specific Health Concerns

$\begin{array}{cccc}\text { Age Group } & \frac{9-11}{n s} & \frac{12-14}{n s} & \frac{15-17}{n s} \\ 6-8 & -- & n s & n s \\ 9-11 & -- & -- & * \\ 12-14 & & n & \end{array}$

Factor 11. Perceived Susceptibility (Specific Conditions)

$6-8$

$9-11$

$12-14$

Factor 1I1. General Health Concern

No Significant Ratios

Factor IV. Perceived Parental Concern

$\begin{array}{llll}6-8 & \text { ns } & \text { ns } & \text { * } \\ 9-11 & -- & \text { ns } & \text { ns } \\ 12-14 & -- & -- & \text { ns }\end{array}$

Factor V. Perceived Seriousness of and Susceptibility to Disease

No Significant Ratios

Factor VI. Perceived Susceptibility (General)

$\begin{array}{lrl}6-8 & \text { ns } & \text { * } \\ 9-11 & -- & \text { ns } \\ 12-14 & -- & -- \\ \star p \leq .05 ; & \star \star p \leq .01 & \end{array}$

measure the "perceived susceptibility" construct into three factors. One of these (factor V) was comprised of items on general susceptibility to disease combined with two items assessing the child's perception of the seriousness of illness. Another susceptibility factor (factor II) was comprised entirely of items relevant to the child's perception of the likelihood that he or she would experience symptoms. The third factor relating to perceived susceptibility (factor IV) was a mix of items concerning the likelihood of experiencing symptoms and items about susceptibility to illness in general.

The three factors relating to susceptibility are thus relatively independent (correlations ranging from .01 to .18), and the items cannot be combined to form an overall index of perceived suceptibility. 
The "specific susceptibility" factor, and the "general susceptibility" factor yielded the highest reliabilities ( .67 and .65 , respectively) It is therefore recommended that the items from these two factors be employed in further research as the core for the measurement of general and specific perceived susceptibility to disease. The finding that some items which were intended to measure perceived severity and some which were intended to measure perceived susceptibility combined into one factor suggests that children's beliefs with respect to these dimensions may not be as differentiated as adults beliefs.

The factor labeled "specific health concerns" (factor I) also exhibited an acceptable level of internal consistency (.77), and was modestly correlated (.22) with the "general susceptibility" factor. As was true for perceived susceptibility, younger children reported a greater degree of concern about health in general. The "specific health concerns" factor could be a measure of "perceived threat." 4 Its slight, positive relationship to the general susceptibility factor is consistent with the Health Belief Model. If the "specific health concerns" factor is accepted as an index of perceived threat, the lower correlations between it and the other two susceptibility factors provides additional support for the argument that the "general susceptibility" factor should be the focus of core items for an index of perceived susceptibility to be used in future research in the area of children's health beliefs.

The factor which has been labeled "general health concerns" (factor III) is characterized by a relatively lower alpha coefficient (.56), and is not significantly related to the age or sex of the child. It shows a fairly high negative relationship $(-.43)$ to "perceived specific susceptibility" (factor II), and is positively related to the factors which have been termed "specific health concerns" (or "perceived threat") and "perceived seriousness of and susceptibility to disease." Further item development and construct validation is needed to test the replicability and necessity of this factor. It may represent general health anxiety, and may serve as a general motivating factor in such behavior as receptivity to, and compliance with, health information (the concept of general health motivation was included in early research on the HBM, but was dropped due to failure to develop operational measures; ${ }^{4}$ it was later revived by Maiman et al.,' but has not received much research attention in the interim).

The final factor to be discussed in the context of the current study is "perceived parental concerns" (factor IV). The reliability coefficient for this factor was low (.26), and if it is to be employed in future research it is suggested that new items be constructed around the two core "perceived parental concern" items which exhibited the 
highest factor loadings. ("How much does your mother/father seem to worry about your health?" and "How much does your mother/father seem to worry about when you get sick?") This factor did, however, show a significant age effect, with six and seven year old children scoring lower than did the other age groups. It remains to be seen if these findings are explained by younger children being less perceptive of parental concerns about their health; by older children being more sensitive regarding such concerns; by parents actually becoming more concerned about the health of their children as these children grow older (perhaps because older children are likely to initiate unhealthy practices), or by other possible alternative explanations. "Perceived parental concerns" also received a negative health loading from an item asking about the child's negative health habits, indicating that children who see their parents as being more concerned about them (or, at least, about their health) engage in fewer detrimental health practices. These results argue in favor of the interpretation that older children become more sensitive to, or perceptive of, their parents' concerns (rather than the hypothesis that older children report higher parental concern because they give their parents more reason for concern).

The hypothesis of decreasing variability in health beliefs with age received only marginal support. In every instance where significant differences in the between-group variances occurred, the younger group showed the greater variance. Only seven of 30 such tests were significant at or beyond the .05 level, however. In five of these seven instances, it was the 6-8 year old children who showed greater variance than did older groups. If these findings prove to be replicable, the indication would be that children's health beliefs are fairly consolidated by the time they reach the third or fourth grade, and any educational intervention directed at altering those beliefs might be more effective during the first elementary school years. This is not to say, however, that modification of beliefs could not be accomplished with older children, but only that they might then offer greater resistance to change.

\section{CONCLUSIONS}

As is clear for both the exploratory nature of the current research and the tentative nature of the above discussion, research in the area of children's health beliefs is still rudimentary. There is sufficient unexplored ground to occupy the attention of health-oriented researchers for some time to come. Nonetheless, if one accepts the premise that behavior is motivated, such efforts are necessary precursors to the planning of successful health behavior intervention efforts. 
It should be noted that there are statistically significant age effects on all factors except one, and in the latter-general health concern - the $P$ value of .06 approaches significance. In the case of five of the six factors, the level of belief or concern decreases with increasing age. Children below age 11 a re more likely to express higher levels of specific concerns, perceived susceptibility to specific conditions, perceived general susceptibility, perceived seriousness of and susceptibility to disease, and general health concern than are children between the ages of 12 and 17 . On the other hand, there is a positive relationship between age and perceived concern of the parents for the child's health.

Generally, if one looks at sub-categories of age, the 6-8 year olds tend to exhibit somewhat lower levels of belief than do the 9-11 year olds. In every case other than that of perceived parental concern, the 9-11 year olds show the highest levels of beliefs and concerns. This finding should be considered along with the data on variability of health belief factors within and across ages. It is clear that, taking the factors as a whole, there is decreasing variability in health beliefs with increasing age. Younger children differ more among themselves in their beliefs than do older children.

It should also be noted that, without exception, no sex differences in level or variability of beliefs are found, nor are there any significant interactions between age and sex. Finally, the items relating to susceptibility split into three separate, relatively independent factors, with the general susceptibility factor (factor IV) showing the greatest internal consistency. A related finding is that some of the items intended to measure perceived severity and some intended to measure perceived susceptibility actually combined to form one factor, suggesting that children's beliefs with respect to these dimensions are not as clearly differentiated as those held by adults.

\section{Research Implications}

The present study findings have both research and substantive implications. One research implication is the necessity to conduct future research on children's health beliefs in the light of the possibility that the perception of susceptibility may comprise three separate dimensions. In addition, one has to consider the possibility that perceptions of susceptibility and of severity are, at early ages, part of a more general concept of what might be labeled "threat," corresponding, in the present study, to factor $V$ : "perceived seriousness of and susceptibility to disease." A final research implication is the desirability of studying children at still younger ages. Admittedly, it is difficult to obtain reliable information from preschool children, but the effort would seem worthwhile when one 
considers that for many of the findings the maximum level of belief is at about the ages of 9-11 (with some falling off at younger and older ages). This suggests that certain health beliefs (and their variability) might be at still lower levels in children 4-6 years of age. If this proved to be true, various programmatic issues could be addressed more intelligently - for example, the issue of whether we would wish to begin educational interventions in the area of health beliefs in preschool children, before they have developed articulated concepts about their own vulnerability to a variety of illness conditions.

\section{Substantive Implications}

The substantive implications of the present research should be viewed in the light of the increasing desire in health education to develop pinpointed, tailored approaches to meet the educational needs of clients. While the profession has long espoused the view that young children offer unprecedented opportunity for effective health education, there has been far less agreement about what that education should comprise in the way of information, beliefs and attitudes.

The present study offers no direct evidence concerning the appropriate informational inputs (e.g., the biological bases of good or poor health), but it does offer some suggestions as to appropriate content for the teaching of beliefs and attitudes. If the results of the present study prove to be stable across other groups, we would not have to establish separate educational programs for boys and girls with regard to components of the $\mathrm{HBM}$, since no sex differences in beliefs were found. We would also know that 6-8 year olds are probably more amenable to development and modification of beliefs than are older groups, since there is a lower absolute level of health beliefs at these younger ages. If we were to learn through subsequent research that these trends extend down to $4-6$ year olds, a strong argument could be made for initiating such educational activities at the preschool level. Of course, it may not be so much that educational interventions to develop or modify health beliefs will have a greater chance of success with 6-8 year olds, but rather, that the cognitive development of 6-8 year olds causes them to process information or cues about health and illness in a manner different from older children. If this were indeed the case, the focus would shift from an emphasis on earlier intervention to a concern with developing interventions appropriate for the child's level of cognitive development

Finally, our educational efforts to develop health belief systems would have to take account of the possibility that the perception of susceptibility, at least at younger ages, may not be sharply 
distinguished from the perception of severity, and that the perception of susceptibility itself may be related to more than one cognitive dimension. Thus, persuading children that they might have a pain in the stomach in the next few months, or a tooth that hurts (from factor II) could not be counted on to generalize to an opinion that they might catch a cold in the next few months or that they might "get sick" (from factor VI).

Viewed independently of other knowledge, the foregoing findings and implications may appear somewhat tenuous since they are based on small numbers. However, the validity of the findings is increased by their concordance with prior research, 12:14 and with developmental theory. Cognitive development is believed to begin with a series of unrelated beliefs which gradually coalesce into groups of global, undifferentiated belief sets, and finally, into differentiated belief systems with articulated parts. It is also generally believed that interventions to modify beliefs are more successfully accomplished for beliefs prior to their differentiation into interrelated systems. The results of this study support the general view that educational interventions to develop or modify health beliefs will have greater success if they are introduced to 6-8 year olds rather than to older groups. Subsequent research, as suggested previously, may reveal that children of even younger ages may successfully be taught the kinds of health beliefs appropriate to adaptation to their environments.

\section{REFERENCES}

1. McKinlay JB: Some approaches and problems in the study of the use of services-an overview. / Health Soc Behav 13:115-152, 1972.

2. Kirscht JP: The Health Belief Model and illness behavior. Health Educ Monogr 2:387-408, 1974

3. Maiman LA. Becker MH: The Health Belief Model: Origins and correlates in psychological theory Health Educ Monogr 2:336-353, 1974

4. Rosenstock IM: Historical origins of the Health Belief Model. Health Educ Monogr 2:328-335, 1974.

5. Becker MH: Psychosocial aspects of health-related behavior. (In) HE Freeman, S. Levine, and LC Reeder (Eds), Handbook of Medica/ Sociology. Englewood Cliffs, N): Prentice-Hall, 1979. pp 253-274

6. Becker $\mathrm{MH}$ : Understanding patient compliance: The contributions of attitudes and other psychosocial factors. (In) SI Cohen(Ed). New Directions in Patient Compliance. Lexington, MA: D.C. Heth and Co, 1979, pp 1-31

7 Maiman LA, et al.: Scales for measuring Health Belief Model dimensions: A test of predictive value, internal consistency, and relationships among beliefs Health Educ Monogr 5:215-230, 1977.

8. Cummings KM, lette AM, Rosenstock IM: Construct validation of the Health Belief Model. Health Educ Monogr 6:394-405, 1978.

9 Lewis MA: Child-initiated care. Am / Nurs 74:652-655, 1974

10. Mechanic D: The influence of mothers on their children's health attitudes and behavior. Pediatr 33:444-453, 1964.

11 Cochman DS: Children's perceptions of vulnerability to illness and accidents. Public Health Rep 85:69-73, 1970. 
12. Cochman DS: Development of health beliefs. Psychol Rep 31.259-266, 1972.

13 Gochman DS: The organizing role of motivation in health beliefs and intentions $/$ Health Soc Behav 13:285-293, 1972

14. Gochman DS, Bagramian RA. Sheiham A Consistency in children's perceptions of vulnerability to health problems Health Serv Rep 87.282-288, 1972

15. Cochman DS. Some correlates of children's health beliefs and potential health behavior 1. Health Soc Behav 12:148-154, 1971

16. Marshall Cl, et al. Attitudes toward health among children of different races and socioeconomic status Pediatr 46.422-426, 1970

17 Campbell 1D Illness is a point of view: The development of children's concepts of illness. Child Devel 46 92-100, 1975

18 Brodic B. Views of healthy children toward illness Am / Public Health 64.1156-1159, 1974

19. Lewis CE, et al. Child-initiated care: The use of school nursing services by children in an "adult-free" system Pediatr 60 499-507. 1977

20 Radius, SM, et al Dysfunctional health behaviors and health belefs of the school-aged child Paper presented at the American Public Health Association. School Health Section, Los Angeles, Californı, 1978

21. Radius SM. et al Adolescents' perspectives on health and illness Paper presented at the American Public Health Association, Maternal and Child Hedith Section. Los Angeles, Californad, 1978

22 Kish L. Survey Sampling. New York, John Wiley and Sons, 1965

23 Thurstone LL: Multiple-Factor Analysis. Chicago: University of Chicago Press, 1947

24 Nunnally IC: Psychometric Theory. New York. McCraw-Hill, 1978

25. Guertın WH. Bailey ir IP Introduction to Modern Factor Analysis. Ann Arbor: Edwards Bros. 1970, pp 195-196.

26 Scheffe HA A method for judging all possible contrasts in the analysis of variance. Biometriha 40:87-104, 195.3

27 McNemar Q: Psychological Statistics. New York: John Wiley and Sons, 162, pp. 249-250. 